\title{
Preferência da broca-das-cucurbitáceas [Diaphania nitidalis Cramer, 1782 (Lepidoptera: Pyralidae)] por cultivares de pepineiro em ambiente protegido
}

\author{
Pickleworm [Diaphania nitidalis Cramer, 1782 (Lepidoptera: Pyralidae)] preference for \\ cucumber cultivars in greenhouse
}

\author{
Giovani Greigh de Brito ${ }^{1}$ Ervandil Corrêa Costa ${ }^{2}$ Heleno Maziero $^{3}$ \\ Andréia Bordini de Brito ${ }^{4}$ Felipe Augusto Dörr ${ }^{5}$
}

\section{- NOTA -}

\section{RESUMO}

A broca-das-cucurbitáceas (Diaphania nitidalis) é uma praga de grande importância em diversas culturas, principalmente do pepineiro. Esta espécie pode apresentar preferência em relação a determinadas cultivares quanto à sua alimentação e até mesmo oviposição. Nesse sentido, o presente estudo objetivou avaliar a ocorrência desta praga em frutos de seis cultivares de pepineiro, em ambiente protegido. As cultivares Patton, Victoria, Premier Vlaspik e Napoleon apresentaram, respectivamente, $50 \%$, $43,75 \%, 37,50 \%, 34,37 \%$ e $25,87 \%$ dos frutos brocados. A cultivar Marinda apresentou resultado promissor, com apenas $10,37 \%$ dos frutos com presença de larvas de D. nitidalis.

Palavras-chave: broca-dos-frutos, Diaphania nitidalis, Cucumis sativus, manejo integrado de pragas, resistência de plantas.

\section{ABSTRACT}

The pickleworm (Diaphania nitidalis) is a major pest on different crops, particulary on cucumber. This species has shown a preference for determined cultivars to its feeding and oviposition habits. Thus, the aim of this study was to evaluate the occurence of D. nitidalis larvae in fruits of six cucumber cultivars in greenhouse. The cultivars Patton, Victoria, Premier, Vlaspik and Napoleon showed, respectively, $50 \%, 43.75 \%, 37.50 \%, 34.37 \%$ and $25.87 \%$ of bored fruits.
Promising results were obtained with the cultivar Marinda, which showed only $10.37 \%$ of bored fruits.

Key words: pickleworm, Diaphania nitidalis, plant resistant, integrated pest management,.

A broca-das-cucurbitáceas (Diaphania nitidalis) está entre as principais pragas do pepineiro. Os maiores danos ocorrem na fase reprodutiva da cultura, quando suas larvas penetram nos frutos, alimentando-se da polpa e tornando-os impróprios para o consumo (CANTLIFFE \& PHATAK, 1975).

Tradicionalmente, o controle de $\boldsymbol{D}$. nitidalis é feito através de aplicações de inseticidas sintéticos. Contudo, o uso contínuo desses produtos torna-se indesejável por vários motivos, dentre os quais se destaca o aparecimento de novas espécies-pragas ou a ressurgência de outras, toxicidade ao homem e inimigos naturais, além do seu elevado custo. Desta forma, o estudo dos aspectos de manejo integrado de pragas (MIP) torna-se cada vez mais importante.

O comportamento diferenciado de insetos frente a genótipos de uma espécie vegetal é um fato que merece atenção. Nesse sentido, torna-se relevante

\footnotetext{
${ }^{1}$ Engenheiro Agrônomo, Aluno do Curso de Pós-graduação em Agronomia, Centro de Ciências Rurais (CCR), Unversidade Federal de Santa Maria (UFSM), Departamento de Defesa Fitossanitária, Sala 3225, 2º andar. Fone: 9987 0091. E-mail: gbrito@mail.ufsm.br. Autor para correspondência.

${ }^{2}$ Engenheiro Agrônomo, Doutor, Professor Titular, Departamento de Defesa Fitossanitária, CCR, UFSM.

${ }^{3}$ Acadêmico de Agronomia, UFSM. E-mail: hmaziero@mail.ufsm.br.

${ }^{4}$ Mestrando em Engenharia de Produção, UFSM.

${ }^{5}$ Mestrando em Bioquímica Toxicológica, UFSM.
} 
a identificação de cultivares que apresentem níveis de resistência a $\boldsymbol{D}$. nitidalis, tendo em vista que esta praga é multivoltina e ocorre durante todo o ciclo do pepineiro. Por isso, esta característica poderia retardar o desenvolvimento da população desta praga, proporcionando a redução do número de aplicações de inseticidas.

Considerando o exposto, o presente estudo objetivou avaliar a preferência da broca-dascucurbitáceas por frutos de seis cultivares de pepineiro utilizadas no Rio Grande do Sul. O estudo foi conduzido na safra de verão 2001/02, em área experimental pertencente ao Departamento de Fitotecnia/UFSM, onde foram avaliadas, em ambiente protegido, as cultivares: Victória, Marinda, Vlaspik, Premier, Patton e Napoleon. Visando excluir a possibilidade de pseudoresistência, as cultivares utilizadas no estudo apresentavam ciclos semelhantes com florescimento e formação de frutos na mesma época, excluindo, portanto, uma eventual assincronia fenológica.

A área experimental constituiu-se de estufa plástica com área útil de $120 \mathrm{~m}^{2}$. As unidades experimentais foram formadas por uma linha com 15 plantas espaçadas de $0,20 \mathrm{~m}$. Utilizou-se delineamento experimental de blocos ao acaso, com 6 tratamentos e 4 repetições.

Para as avaliações, realizou-se a colheita dos frutos, a cada dois dias, durante todo o período de produção das cultivares. Após cada colheita, procedeu-se a contagem do número total de frutos e de broqueados por parcela. Os valores obtidos foram transformados em porcentagem média de frutos broqueados. Para confirmação da espécie, os frutos atacados foram levados ao Laboratório de Entomologia do Departamento de Defesa Fitossanitária, onde foram colocados em gaiolas de vidro com $0,25 \mathrm{~m}$ de diâmetro e $0,40 \mathrm{~m}$ de altura, realizando-se a identificação por ocasião da emergência da fase adulta. As porcentagens de frutos broqueados foram transformados em $\operatorname{arc~sen} \sqrt{\%}$ visando sua normalização e adequação para a análise estatística. A variável analisada foi submetida à análise de variância pelo "Teste F" e a comparação de médias foi realizada através do teste de Duncan ao nível de 5\% de probabilidade de erro.

As cultivares Patton, Victoria, Premier e Vlaspik apresentaram elevada incidência de frutos brocados, sendo que ao redor de $35 \%$ ou até metade da produção estaria comprometida (Tabela 1). Já a cultivar Napoleon, apesar de apresentar resultado estatisticamente equivalente às três últimas (Victoria, Premier e Vlaspik), apresentou menor incidência de frutos broqueados em relação à Patton. Por sua vez, a cultivar Marinda apresentou, estatisticamente,
Tabela 1 - Porcentagem de frutos brocados por Diaphania nitidalis em seis cultivares de pepineiro em ambiente protegido. Santa Maria, RS. 2001/02.

\begin{tabular}{lccc}
\hline & Cultivares & \multicolumn{2}{c}{ Frutos brocados $(\%)$} \\
\hline 1 & Patton & 50,00 & $\mathrm{a}^{1}$ \\
2 & Victoria & 43,75 & $\mathrm{ab}$ \\
3 & Premier & 37,50 & $\mathrm{ab}$ \\
4 & Vlaspik & 34,37 & $\mathrm{ab}$ \\
5 & Napoleon & 25,87 & $\mathrm{~b}$ \\
6 & Marinda & 10,37 & $\mathrm{c}$ \\
& $\mathrm{CV}(\%)$ & & 24,40 \\
\hline
\end{tabular}

${ }^{1}$ Médias não seguidas da mesma letra na coluna diferem entre si pelo teste de Duncan em nível de 5\% de probabilidade de erro.

vantagem em relação às demais, observando-se apenas $10,37 \%$ dos frutos com presença de larvas durante todo o seu período produtivo. A cultivar Marinda apresenta menor incidência de frutos broqueados em relação às cultivares testadas, merecendo mais estudos que identifiquem os mecanismos de resistência responsáveis por este comportamento. Nesta mesma linha, pesquisas têm sido desenvolvidas com o propósito de elucidar os fatores químicos envolvidos na preferência da broca-das-cucurbitáceas por espécies ou até mesmo por cultivares da família Cucurbitaceae. Os resultados obtidos nestes estudos sugerem que compostos voláteis e não-voláteis, produzidos pelas plantas, determinariam a preferência de oviposição pela praga em questão. Através da aplicação de modernas técnicas cromatográficas visando o isolamento destes compostos constatouse que os compostos não-voláteis (aminoácidos nãoprotéicos) produzidos por cucurbitáceas comportamse como estimulantes de oviposição e que os compostos voláteis estariam mais envolvidos na atração dos insetos às plantas hospedeiras do que propriamente na oviposição (PETERSON \& ELSEY, 1995).

Deste modo, a composição e a concentração relativa destes aminoácidos não-protéicos, produzidos pelas cucurbitáceas, poderiam determinar a especificidade de $\boldsymbol{D}$. nitidalis por diferentes cultivares de pepineiros, todavia, novos estudos visando elucidar os mecanismos de resistência responsáveis pela preferência de oviposição e a interação destes mecanismos com os inimigos naturais dessa praga necessitam ser desenvolvidos.

\section{REFERÊNCIAS BIBLIOGRÁFICAS}

CANTLIFFE, D.J.; PHATAK, S.C. Plant population studies with pickling cucumbers grown for once-over harvest. 
Journal of the American society for Horticultural Science, Mount Vernon, v.100, n.5, p.464-466, 1975.

GALLO, D. et al. Manual de entomologia agrícola. São Paulo : Ceres, 1988. 649p.
PETERSON, J.K.; ELSEY, K.D. Chemical factors involved in selection of host plant for oviposition by the pickleworm moth (Lepidoptera: Pyralidae). Florida Entomologist, Florida, v.78, n.3, p.482-492, 1995 . 